\title{
$\lg G$ and $\lg G$ subclass antibodies in patients with active cutaneous leishmaniasis
}

\section{Correspondence \\ Suleyman Yazar \\ syazar@erciyes.edu.tr}

Received 7 April 2006

Accepted 9 May 2006

\author{
Hatice Ozbılge, ${ }^{1}$ Nurten Aksoy, ${ }^{2}$ Mehmet S. Gurel ${ }^{3}$ and Suleyman Yazar ${ }^{4}$ \\ ${ }^{1,4}$ Department of Pharmaceutical Microbiology ${ }^{1}$ and Faculty of Pharmacy and Parasitology ${ }^{4}$, \\ Faculty of Medicine, Erciyes University, Kayseri, Turkey \\ 2,3 Departments of Biochemistry ${ }^{2}$ and Dermatology ${ }^{3}$, Harran University Medical Faculty, Sanliurfa, \\ Turkey
}

This research was planned to detect $\lg G$ and $\lg G$ subclasses in sera of patients with active cutaneous leishmaniasis (CL). Sera from 30 patients with active $C L$ aged between 10 and 50 years and from 30 healthy controls aged between 8 and 50 years were included in the study. Levels of $\lg G$ and its subclasses were measured by a nephelometer. Levels of $\lg G, \lg G 1$ and $\lg G 3$ in the CL patients were higher than in the controls. In addition, IgG and $\lg G 1$, and $\lg G$ and $\lg G 3$ levels showed a significant positive correlation. These results showed that IgG subclasses could possibly be used as a helpful diagnostic marker in CL.

\section{INTRODUCTION}

Leishmania spp. are obligately intracellular protozoa that cause a spectrum of diseases, including cutaneous (CL), mucocutaneous and visceral leishmaniasis (VL) (Trujillo et al., 1999). Sanliurfa is an area highly endemic for CL caused by the protozoan Leishmania tropica and for many years it has been an important focus in southern Anatolia, Turkey (Gurel et al., 2002). A lot of research to understand the varied aspects of regulation in the immune system has been focused on the immunopathology of leishmanial infections. With respect to the humoral immune response, a successively higher specific antibody titre can be observed in localized CL, mucocutaneous leishmaniasis and diffuse CL. The intensity of the antibody response appears to reflect both the parasite load and the chronicity of the infection (Gutierrez et al., 1991). An exceptionally high antibody titre against Leishmania antigens can be detected in the most severe form of disease, $\mathrm{VL}$, as a consequence of polyclonal activation of $B$ cells as a result of the presence of large numbers of parasites in the bone marrow and spleen (Galvao-Castro et al., 1984).

It has been shown that IgG not only fails to provide protection against this intracellular pathogen, but that it actually contributes to disease progression (Miles et al., 2005). In addition, studies have shown that large CL lesions were correlated with a higher frequency of lymphocytes producing Leishmania soluble antigen specific inflammatory cytokines (IFN- $\gamma$ or TNF- $\alpha$ ) (Antonelli et al., 2005).

Analysis of Leishmania antigen-specific immunoglobulin isotypes and IgG subclasses in VL patient sera revealed

Abbreviations: $\mathrm{CL}$, cutaneous leishmaniasis; VL, visceral leishmaniasis. elevated levels of IgG, IgM, IgE and IgG subclasses during disease (Atta et al., 1998; Anam et al., 1999a; da Matta et al., 2000; Ryan et al., 2002; Ravindran et al., 2004). The differential patterns of immunoglobulin isotypes observed during disease progression, drug resistance and cure were specific for antigens of Leishmania donovani. IgG subclass analysis revealed expression of all of the subclasses, with a predominance of IgG1 during disease (Anam et al., 1999b). The role of antibody titres in resolution of CL and protective immunity is largely unknown. Although some studies have shown the advantage of using specific subclass antibodies for the diagnosis of VL, only a few reports are available for CL. The goal of this study is to evaluate serum IgG levels and IgG subclass distribution and the correlation between them in CL patients, and to find out whether this may be used as a helpful diagnostic tool for this disease.

\section{METHODS}

Patients. This study was conducted at the Harran Kapi Leishmania Center in Sanliurfa, southern Anatolia, Turkey. Sixty people were included (30 patients with CL and 30 healthy controls selected from the same region) in this study. The control group was selected from healthy volunteers (19 females and 11 males aged 8-50) who had not been exposed to CL. The patient group ( 21 females and 9 males aged 10-50) was selected from people who had come to the Harran Kapi Leishmaniasis Center for CL therapy. The patients were not under treatment at the time of study. Patients were selected with active CL, i.e. had lesions that were wet, large in size and mostly ulcerated for less than 3 months. Before blood collections all patients were informed about the content of the study and a written agreement was obtained from all of them. They were diagnosed by established clinical and epidemiological criteria. Diagnosis had been confirmed by direct microscopy after staining with Giemsa and by parasite culture in NNN (Novy, Nicolle, Neal) medium (15\% 
defibrinated rabbit blood and $200 \mathrm{U}_{\text {penicillin }} \mathrm{ml}^{-1}$ ). Cultures were incubated at $25^{\circ} \mathrm{C}$ and checked for growth of Leishmania promastigotes twice a week.

Immunoglobulin analysis. All venous blood samples were collected in polystyrene tubes. The tubes were centrifuged at $500 \mathrm{~g}$ for $15 \mathrm{~min}$. Serum was then removed and stored at $-20^{\circ} \mathrm{C}$ until use. IgG and IgG subclass levels were measured with a nephelometer (Behring 100) according to the protocol provided by the manufacturer with a commercially available kit (Behring Diagnostics).

Statistical analysis. Data were analysed using the program SPSS 10.0 for Windows. Parametric statistical methods were used to analyse the data. The Student's $t$-test was used for pairwise comparisons. Bivariate comparisons were examined using Pearson rank correlation coefficients $(r)$ and values were corrected for duplicates. Two-tailed significance values were used. A $P$ value of 0.05 or less was considered to be significant.

\section{RESULTS}

IgG and IgG subclass levels were measured both in patients with active $\mathrm{CL}$ and in healthy controls, and the results were then compared with each other (Table 1). In our study, IgG, IgG1 and IgG3 levels were significantly higher in sera of the patients with active CL than in sera of the control group $(P<0 \cdot 001$ for all). There was no statistically significant difference between the sera IgG2 and IgG4 levels of the study groups $(P>0 \cdot 05)$. A high correlation between IgG and IgG1 levels $(r=0.805, P<0.001)$ and a weaker correlation between IgG and IgG3 levels $(r=0 \cdot 404, P<0 \cdot 05)$ was found. There was no significant correlation between IgG and its other subclasses, or among the IgG subclasses.

\section{DISCUSSION}

Cytokines elaborated by activated $\mathrm{T}$ cells induce the switching of B lymphocytes to several IgG isotypes and are thus obligatory for some humoral responses. IFN $-\gamma$, the Th1 cytokine, probably upregulates IgG1 and IgG3 in humans. IL-4 and IL-5 and Th2 cytokines stimulate the production of high levels of IgG subclasses such as IgG1 (Reiner \& Locksley, 1995; Abbas et al., 1996; Rothman \& Coffman, 1996). Little information is currently available about IgG subclass distribution in human CL. In this study, we aimed to explore the distribution of IgG and its subclasses in active CL cases and to ascertain whether this

Table 1. Comparison of serum $\lg G$ and $\lg G$ subclass levels of patients with active $\mathrm{CL}$ and controls (mean \pm SD)

\begin{tabular}{|lccl|}
\hline Parameter & $\begin{array}{c}\text { Controls } \\
(\boldsymbol{n}=\mathbf{3 0})\end{array}$ & $\begin{array}{c}\text { Patients with CL } \\
(\boldsymbol{n}=\mathbf{3 0})\end{array}$ & $\boldsymbol{P}$ value \\
\hline IgG $\left(\mathrm{g} \mathrm{l}^{-1}\right)$ & $12 \cdot 196 \pm 0 \cdot 52$ & $16 \cdot 894 \pm 0 \cdot 81$ & $P<0 \cdot 001$ \\
IgG1 $\left(\mathrm{g} \mathrm{l}^{-1}\right)$ & $8 \cdot 069 \pm 0 \cdot 35$ & $13 \cdot 657 \pm 0 \cdot 72$ & $P<0 \cdot 001$ \\
IgG2 $\left(\mathrm{g} \mathrm{l}^{-1}\right)$ & $2 \cdot 087 \pm 0 \cdot 16$ & $2 \cdot 440 \pm 0 \cdot 19$ & $P>0 \cdot 05$ \\
IgG3 $\left(\mathrm{g} \mathrm{l}^{-1}\right)$ & $0 \cdot 711 \pm 0 \cdot 05$ & $1 \cdot 403 \pm 0 \cdot 15$ & $P<0 \cdot 001$ \\
IgG4 $\left(\mathrm{g} \mathrm{l}^{-1}\right)$ & $0 \cdot 299 \pm 0 \cdot 03$ & $0 \cdot 322 \pm 0 \cdot 02$ & $P>0 \cdot 05$ \\
\hline
\end{tabular}

can be used as a diagnostic marker for this disease. In agreement with a recent report in the literature (Skeiky et al., 1997), levels of all IgG subclasses were increased in the sera of patients with active CL, but IgG1 and IgG3 appeared to be predominant.

The possible role of antibody-mediated protection against Leishmania signifies the importance of identification of antigens that may elicit protective antibodies. Post-treatment VL sera tested for most of the IgG subclasses indicate a potential role of gp63 in protection against this disease (Ravindran et al., 2004). We previously characterized parasite cell surface antigens of CL and identified at least four antigenic structures different in size and biochemical composition (Aksoy et al., 2004).

Results obtained by Deplazes et al. (1995) appear to support the data obtained from this present study. They showed that there were increased levels of IgG subclasses with a predominance of IgG1 and IgG3 in patients with active CL. Our results strongly suggest that levels of $\operatorname{IgG}$ and its subclasses, particularly IgG1 and IgG3, in sera of patients with active CL are significantly upregulated and may have an important role in the antibody-dependent defence mechanisms of the host against CL.

In the light of these findings, it should be possible to conclude that in human CL, levels of IgG and all its subclasses (IgG1 and IgG3 predominantly) are upregulated, and that there is a significant correlation between IgG and IgG1, and between IgG and IgG3 isotypes. We may also conclude that measurement of the sera concentrations of these immunoglobulins could be used as a diagnostic or prognostic marker to evaluate patients with active CL. To ascertain this, complex studies with a higher number of patients obviously need to be planned.

\section{REFERENCES}

Abbas, A. K., Murphy, K. M. \& Sher, A. (1996). Functional diversity of helper T lymphocytes. Nature 383, 787-793.

Aksoy, N., Ozbilge, H., Keles, S., Iriadam, M., Vural, H. \& Akcay, F. (2004). A preliminary approach to the separation of Leishmania cellsurface antigens. J Sep Sci 27, 1011-1016.

Anam, K., Afrin, F., Banerjee, D., Pramanik, N., Guha, S. K., Goswami, R. P., Saha, S. K. \& Ali, N. (1999a). Differential decline in Leishmania membrane antigen-specific immunoglobulin $\mathrm{G}(\mathrm{IgG})$, IgM, IgE, and IgG subclass antibodies in Indian kala-azar patients after chemotherapy. Infect Immun 67, 6663-6669.

Anam, K., Afrin, F., Banerjee, D., Pramanik, N., Guha, S. K., Goswami, R. P., Gupta, P. N., Saha, S. K. \& Ali, N. (1999b). Immunoglobulin subclass distribution and diagnostic value of Leishmania donovani antigen-specific immunoglobulin G3 in Indian kala-azar patients. Clin Diagn Lab Immunol 6, 231-235.

Antonelli, L. R., Dutra, W. O., Almeida, R. P., Bacellar, O., Carvalho, E. M. \& Gollob, K. J. (2005). Activated inflammatory T cells correlate with lesion size in human cutaneous leishmaniasis. Immunol Lett 101, 226-230. 
Atta, A. M., D'Oliveira, A., Correa, J., Atta, M. L., Almeida, R. P. \& Carvalho, E. M. (1998). Anti-leishmanial IgE antibodies: a marker of active disease in visceral leishmaniasis. Am J Trop Med Hyg 59, 426-430.

da Matta, V. L., Hoshino-Shimizu, S., Dietze, R. \& Corbett, C. E. (2000). Detection of specific antibody isotypes and subtypes before and after treatment of American visceral leishmaniasis. J Clin Lab Anal 14, 5-12.

Deplazes, P., Smith, N. C., Arnold, P., Lutz, H. \& Eckert, J. (1995). Specific IgG1 and IgG2 antibody responses of dogs to Leishmania infantum and other parasites. Parasite Immunol 17, 451-458.

Galvao-Castro, B., Sa Ferreira, J. A., Marzochi, K. F., Marzochi, M. C., Coutinho, S. G. \& Lambert, P. H. (1984). Polyclonal B cell activation, circulating immune complexes and autoimmunity in human american visceral leishmaniasis. Clin Exp Immunol 56, 58-66.

Gurel, S., Ulukanlıgil, M. \& Ozbilge, H. (2002). Cutaneous leishmaniasis in Sanliurfa: epidemiologic and clinical features of the last four years (1997-2000). Int J Dermatol 41, 32-37.

Gutierrez, Y., Salinas, G. H., Palma, G., Valderrama, L. B., Santrich, C. V. \& Saravia, N. G. (1991). Correlation between histopathology, immune response, clinical presentation, and evolution in Leishmania braziliensis infection. Am J Trop Med Hyg 45, 281-289.

Miles, S. A., Conrad, S. M., Alves, R. G., Jeronimo, S. M. \& Mosser, D. M. (2005). A role for IgG immune complexes during infection with the intracellular pathogen Leishmania. J Exp Med 201, 747-754.
Ravindran, R., Anam, K., Bairagi, B. C., Saha, B., Pramanik, N., Guha, S. K., Goswami, R. P., Banerjee, D. \& Ali, N. (2004). Characterization of immunoglobulin $G$ and its subclass response to Indian kala-azar infection before and after chemotherapy. Infect Immun 72, 863-870.

Reiner, S. L. \& Locksley, R. M. (1995). The regulation of immunity to Leishmania major. Annu Rev Immunol 13, 151-177.

Rothman, P. \& Coffman, R. L. (1996). Immunoglobulin heavy chain class-switching. In Weir's Handbook of Experimental Immunology, 5th edn, pp. 191-194. Edited by L. A. Herzenberg. Oxford: Blackwell Scientific Publications.

Ryan, J. R., Smithyman, A. M., Rajasekariah, G. H., Hochberg, L., Stiteler, J. M. \& Martin, S. K. (2002). Enzyme-linked immunosorbent assay based on soluble promastigote antigen detects immunoglobulin $\mathrm{M}$ (IgM) and $\operatorname{IgG}$ antibodies in sera from cases of visceral and cutaneous leishmaniasis. J Clin Microbiol 40, 1037-1043.

Skeiky, Y. A., Benson, D. R., Costa, J. L., Badaro, R. \& Reed, S. G. (1997). Association of Leishmania heat shock protein 83 antigen and immunoglobulin G4 antibody titers in Brazilian patients with diffuse cutaneous leishmaniasis. Infect Immun 65, 5368-5370.

Trujillo, C., Ramirez, R., Velez, I. D. \& Berberich, C. (1999). The humoral immune response to the kinetoplastid membrane protein-11 in patients with American leishmaniasis and Chagas disease: prevalence of IgG subclasses and mapping of epitopes. Immunol Lett 70, 203-209. 